\title{
Conservative management of ovarian torsion in pregnancy
}

\section{Rama Garg, Sangeeta Rani*, Sambli Garg}

Department of Obstetrics and Gynecology, GMC, Patiala, Punjab, India

Received: 18 June 2019

Revised: 22 September 2019

Accepted: 30 September 2019

\section{* Correspondence:}

Dr. Sangeeta Rani,

E-mail: drramagarg@gmail.com

Copyright: (c) the author(s), publisher and licensee Medip Academy. This is an open-access article distributed under the terms of the Creative Commons Attribution Non-Commercial License, which permits unrestricted non-commercial use, distribution, and reproduction in any medium, provided the original work is properly cited.

\begin{abstract}
Adnexal torsion or other cyst accidents encountered during pregnancy carries a risk to intrauterine foetus. Delays or misdiagnosis can result in the loss of the affected ovary and subsequent reduced reproductive capacity. In this report, a 23-year-old second gravida with viable 9 weeks pregnancy with acute pain abdomen; presented in OPD and sent to labor room. Emergency laprotomy was done with provisional diagnosis of left adnexal torsion. We did detorsion and cystectomy followed by ovarian reconstruction. Repeat scan shows continuing intrauterine pregnancy. So, timely diagnosis and intervention reduces risk to ovary; along with some risk of the antepartum surgical intervention. Also, in place of oophorectomy; de-torsion is more conservative surgical approach that should be considered in all young women with ovarian torsion.
\end{abstract}

Keywords: Cystectomy, Detorsion, Laparotomy, Ovarian torsion, Ovarian cyst, Pregnancy

\section{INTRODUCTION}

Adnexal torsion or other cyst accidents usually present with acute pelvic pain. Between $2.5 \%$ and $7.4 \%$ of patients undergoing emergency surgery for acute pelvic pain are found to have proven ovarian torsion. ${ }^{1}$ Diagnosis can be difficult as clinical presentation varies and is mainly based on clinical symptoms and imaging techniques such as ultrasound and MRI. Delay or misdiagnosis can result in the loss of the affected ovary and subsequent reduced reproductive capacity. ${ }^{2} \mathrm{~A}$ normal ultrasound scan does not exclude adnexal torsion and the decision to operate should be made on clinical grounds if symptoms are severe. ${ }^{2}$ Also, removal of the ovary containing the corpus luteum in early pregnancy may lead to miscarriage. ${ }^{3}$ Adenexectomy was traditionally the treatment of choice because of the theortical risk of thromboembolism. This has now been refuted. Now, the aim of surgery is thus to recover viable ovarian tissue by urgently untwisting the pedicle and restoring the blood flow to the area plus excision of any contributing ovarian cyst as second procedure. ${ }^{1}$ In this report, more conservative surgical approach of untwisting the torsion followed by cystectomy with ovarian tissue reconstruction for successful outcome of early pregnancy.

\section{CASE REPORT}

A 23-year-old female second gravida who had delivered her first child by normal vaginal delivery 9 month back; presented in emergency with chief complaints of pain abdomen and vomiting since morning (6-7 hours). She was carrying 9 weeks pregnancy. On examination, her vitals were normal. On per abdomen examination, abdomen was soft; and there was large globular ballotable tender cystic mass about $7 \times 8 \mathrm{~cm}$ present in left lumber region extending to under umbilicus. There was no guarding and rigidity. On per vagium examination, 
uterus was 10 weeks size; soft; deviated to right. Left fornix was free, and a cystic mass was lying high up on left side. Mass could not be felt through left fornix. So, provisional diagnosis of pregnancy with left adnexal torsion was made. She was investigated, her hemoglobin was $10 \mathrm{gm} \%$; patient had ca 125 level $81 \mathrm{u} / \mathrm{ml}$. On ultrasound scanning, there was a single intrauerine gestational sac with yolk sac with foetal pole (CRL 9 weeks 1 day) with presence of cardiac activity. Both ovaries: right ovary was normal in size and showed small folicles; on left side, a large hypoechoeic mass with cystic component seen superior to the fundal region reaching up to the umbilicus. It measured approx $84.2 \times 63$ $\mathrm{mm}$ in size with no evidence of vasculariy with in the mass and at the margins. Left ovarian parenchyma was seen lying adjacent to it, suggestive of ? torsion ovary ?? complex hemorrhagic cyst. There was no free fluid in cul de sac. Finally, the decision of urgent laprotomy was taken after consent regarding risk of antepartum surgical intervention. On opening abdomen, there was ovarian cyst torsion on left side at the level of mesovarium of about full one turn (360 degree) (Figure 1). Untwisting of torsion done followed by cystectomy of hemorrhagic cyst (Figure 2) with ovarian reconstruction of viable tissue by inverting sutures (vicryl 4-0) (Figure 3). Right ovary was normal. Her postoperative period was uneventful. She was administered injection hydroxyprogesterone acetate $500 \mathrm{mg}$ stat. Repeat scan on $7^{\text {th }}$ postoperative day shows a viable pregnancy. The histopathology report of cyst removed showed nonviable tissue. Therefore, final diagnosis of early pregnancy with ovarian torsion and hemorrhagic corpus luteal cyst was made. She was discharged under satisfactory condition with advice of folic acid $5 \mathrm{mg}$ and injection Hydroxyprogestrone maintain weekly till 12 weeks.

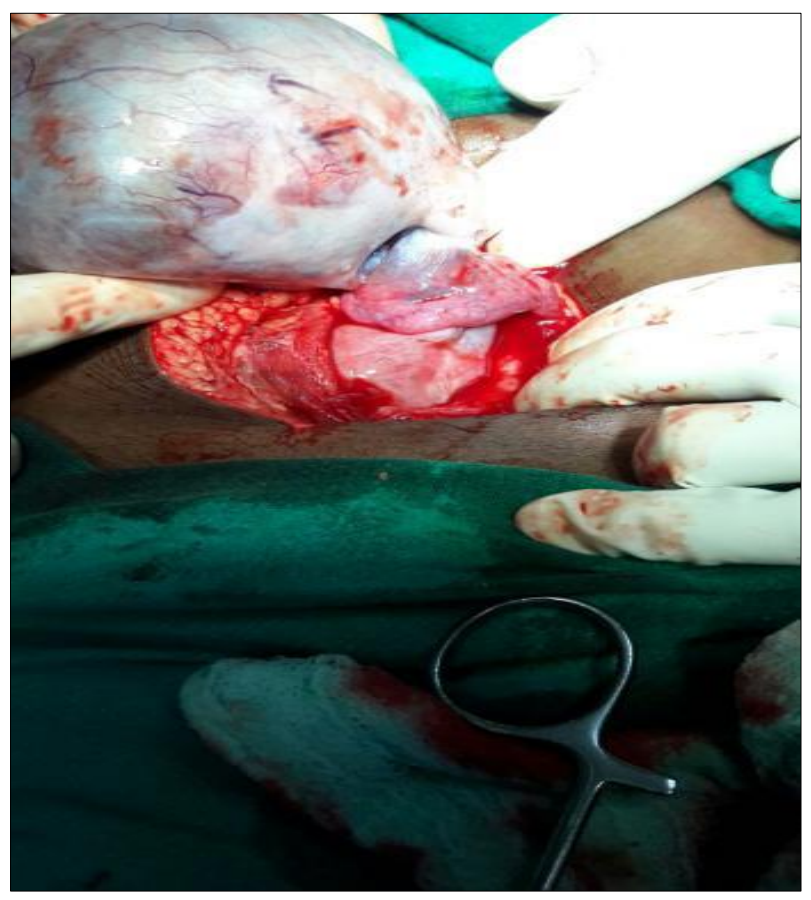

Figure 1: Torsion ovarian cyst by 360 degree.

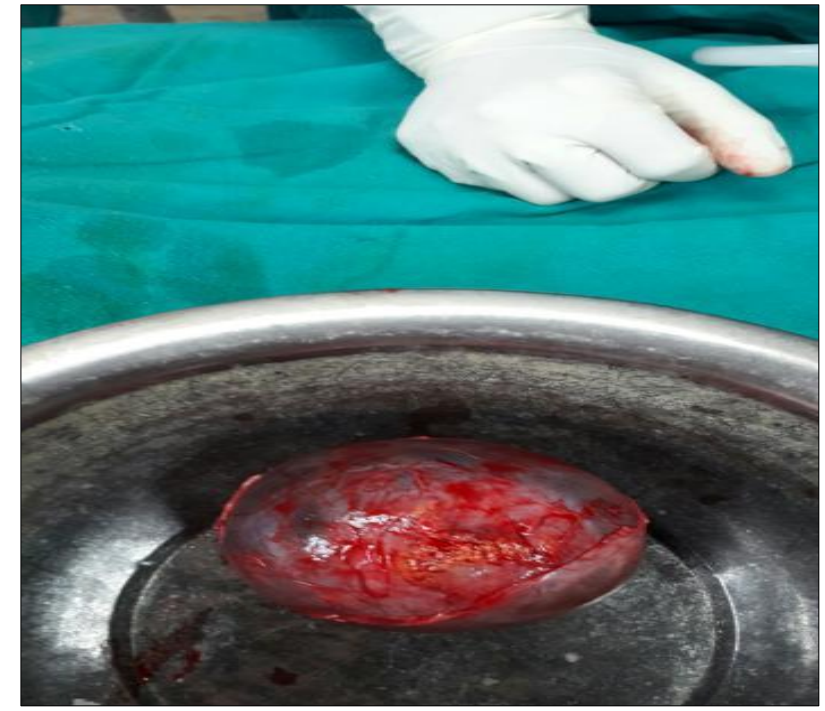

Figure 2: Ovarian cyst.

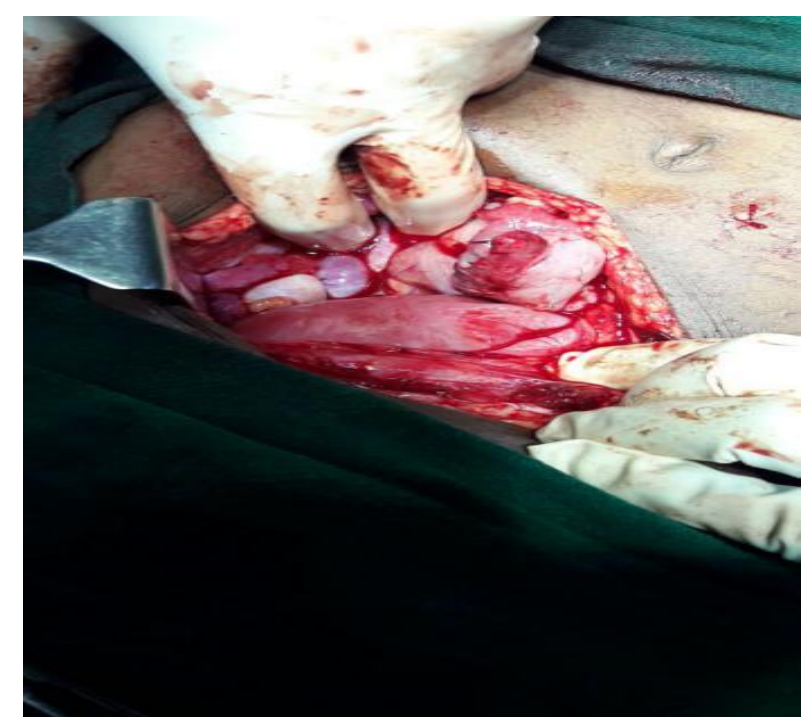

Figure 3: Reconstruction of ovary.

\section{DISCUSSION}

Torsion of the ovary, tube or both is estimated to be responsible for only a small number of all gynaecological emergencies, but is a common diagnostic challenge in the emergency setting. ${ }^{2}$ It can be defined as 'the twisting by least one complete turn of the adnexa, ovary or more rarely tube alone, around central line consisting of the infundibulopelvic and tubo-ovarian ligaments'. The right side is more frequently affected than left side. Factors that increase the risk of torsion include benign ovarian cysts, ovarian hyperstimulation and first trimester of pregnancy. ${ }^{1}$ Torsion is more common in prepubertal girls, during pregnancy and puerperium due to the laxity of tissues. The usual presentation is with acute onset pelvic pain, nausea, vomiting, tachycardia and low-grade fever. Atypical presentation can lead to mis-diagnosis or delay in diagnosis, resulting in the loss of ovarian function in many cases. $^{3}$ Diagnosis of ovarian torsion requires 
clinician awareness and a high degree of suspicion. It is presently based on clinical symptoms and physical examination. However, the clinical findings of ovarian torsion frequently overlap with other causes of pelvic pain and adnexal masses, including hemorrhagic cysts and abscesses. Sonography is usually the first imaging modality used in the evaluation of a patient with pelvic pain. The sonographic appearance of a torsed adnexa may be solid, cystic, or complex. The ovary shows one or more cystic follicles with marked thickening of the cyst wall; it is usually diffusely enlarged. ${ }^{4}$ The most consistent finding is a unilateral enlarged ovary (as qouted by many reports). ${ }^{2-5}$ Comparison with the asymptomatic contralateral side is typically very helpful. However, the presence of normal-appearing ovaries does not rule out the diagnosis of adnexal torsion. Findings on color Doppler imaging are not consistent because of the variable degree of torsion; however, ovarian torsion rarely manifests with completely normal venous waveforms. The presence of central venous flow and flow in the vascular pedicle may indicate ovarian viability. Other telltail findings on both gray scale and color Doppler sonography are a twisted vascular pedicle and the whirlpool sign. ${ }^{2,4}$ in our case, there was absence of flow to mass within and at the margins.

The surgical management of adnexal torsion is clearly determined by many factors in addition to the macroscopic appearance of the adnexum; including age, menopausal status, presence of pre-existing ovarian pathology and desire to preserve fertility. In the past, surgery was involved partial or complete oophorectomy or salpingo-oophorectomy. There is evidence to support conservative management with laparoscopic de-torsion in the majority of cases with little short or long-term associated morbidity. ${ }^{2,3,5}$

The likelihood of preserving viable ovarian tissue with conservative surgery (de-torsion) decreases over time, with some evidence that pain for longer than 48 hours is associated with a significant decrease in successful outcome. Follow up of women who have undergone detorsion, suggests that in the majority of cases, function appears to recover (based on the presence of follicular activity on follow-up ovarian ultrasound, pregnancy rates). ${ }^{2}$

Although the role of oophoropexy after detorsion is not clear, it is mostly recommended in patients with recurrent torsion or children and adolescents with torsion of normal ovary. $^{2}$

In all cases of adnexal torsion, the laparoscopic approach would be the preferred route in order to reduce admission time, postoperative pain and long-term risk of adhesion formation. ${ }^{2,6}$ However, the route should be determined by the clinical expertise of the operator, and based on the patients' suitability for laparoscopic surgery.

\section{CONCLUSION}

Adnexal torsion should be suspected in women with acute pelvic pain. Physical examination may elicit an adnexal mass or adnexal tenderness but can be nonspecific. So, ultrasound remains the first-line investigation. The absence of radiological evidence suggestive of torsion does not necessarily exclude it and the decision to operate should be on clinical grounds if symptoms are severe. In our report, timely diagnosis followed by early intervention (within 48 hours) have helped in conserving patient's adnexa by the means of detorsion which seems to be beneficial for women in long run. Now a days more conservative approach is opted rather than oopherectomy along with oophorpexy. But our case authors did only detorsion followed by cystectomy via minilaprotomy; resulting in successful outcome.

\section{Funding: No funding sources \\ Conflict of interest: None declared \\ Ethical approval: Not required}

\section{REFERENCES}

1. Book chapter: Borley J, Farthing A. The Ovaries. In: Setchell ME, Shepherd JH, eds. Shaw's Textbook of Operative Gynaecology. $7^{\text {th }}$ ed. London, UK: Elsevier; 2013:195-200.

2. Damigos E, Johns J, Ross J. An update on the diagnosis and management of ovarian torsion. The Obstet Gynecol. 2012;14:229-36.

3. Mathew M, Mubarak SA, Jesrani SK. Conservative management of twisted ischemic adnexa in early pregnancy. AMHSN. 2015;5(2):142-4.

4. Mashiach R, Melamed N, Gilad N, Ben-Shitrit G, Meizner I. Sonographic diagnosis of ovarian torsion: accuracy and predictive factors. J Ultrasound Med. 2011;30(9):1205-10.

5. Nasiri A, Rahimi S, Tomlinson E. Ovarian torsion in pregnancy: a case report. Gynecol Obstet Case Rep. 2017;3:2.

6. Karayalçın R, Özcan S, Özyer Ş, Var T, Yeşilyurt H, Dumanlı $\mathrm{H}$, et al. Conservative laparoscopic management of adnexal torsion. J Turkish German Gynecol Asso. 2011;12(1):4.

Cite this article as: Garg R, Rani S, Garg S.

Conservative management of ovarian torsion in pregnancy. Int J Reprod Contracept Obstet Gynecol 2019;8:4606-8. 